\title{
Formaldehyde and methylamine reactivity in interstellar ice analogues as a source of molecular complexity at low temperature
}

\author{
V. Vinogradoff, F. Duvernay, G. Danger, P. Theulé, F. Borget, and T. Chiavassa
}

\author{
Université d'Aix-Marseille, Laboratoire de Physique des Interactions Ioniques et Moléculaires, UMR CNRS 7345, \\ Centre de St-Jérôme, Avenue Escadrille Normandie-Niemen, 13397 Marseille Cedex 20, France \\ e-mail: fabrice.duvernay@univ-amu.fr
}

Received 9 July 2012 / Accepted 24 October 2012

\begin{abstract}
Context. Laboratory simulations on interstellar or cometary ice analogues are crucial to understand the formation of complex organic molecules that are detected in the interstellar medium (ISM). Results from this work give hints on physical and chemical processes occurring in space and can serve as a benchmark for dedicated space missions.

Aims. The aim of this work is to consolidate the knowledge of ice evolution during the star formation process by investigating the influence of thermal reactions as a source of molecular complexity in the ISM. In this study, we are interested in the thermal reactivity between two interstellar molecules, formaldehyde $\left(\mathrm{H}_{2} \mathrm{CO}\right)$ and methylamine $\left(\mathrm{CH}_{3} \mathrm{NH}_{2}\right)$ in water ice analogues.

Methods. We used Fourier transform infrared spectroscopy, mass spectrometry, and B3LYP calculations to investigate the thermal reaction between formaldehyde and methylamine $\left({ }^{14} \mathrm{~N}\right.$ and $\left.{ }^{15} \mathrm{~N}\right)$ at low temperature in water ice analogues.

Results. We demonstrate that methylamine and formaldehyde quickly react in water ice analogues for astronomically relevant temperatures and form $\mathrm{N}$-methylaminomethanol $\mathrm{CH}_{3} \mathrm{NHCH}_{2} \mathrm{OH}$. The measured activation energy of this reaction, $1.1 \pm 0.05 \mathrm{~kJ}^{\mathrm{mol}}{ }^{-1}$ $\left(1.8 \pm 0.08 \mathrm{~kJ} \mathrm{~mol}^{-1}\right.$ with methylamine $\left.{ }^{15} \mathrm{~N}\right)$, allows the reaction to proceed in interstellar ices, when the ices are gently warmed, as it occurs in young stellar objects, in photo-dissociation regions, or in comets. Therefore, $\mathrm{CH}_{3} \mathrm{NHCH}_{2} \mathrm{OH}$ is likely to be found in these objects. This hypothesis is confirmed by numerical simulations that clearly show that the formation of N-methylaminomethanol is likely at low temperature. Isotopic experiments as well as photochemical studies have also been performed to better characterise the ice evolution induced by heat and ultraviolet radiation during star formation.
\end{abstract}

Key words. astrochemistry - molecular processes - methods: laboratory - ISM: molecules

\section{Introduction}

Star formation begins with the collapse of a prestellar core inside a molecular cloud to form a protostar, which then grows from material coming from its envelope, and later through an accretion disk, where planets and comets may form. This physical evolution from the molecular cloud to a planetary system is accompanied by chemical evolution induced by heat and ultraviolet (UV) or X-rays radiations from the protostar. Much of this chemical evolution takes place in the icy mantle of interstellar grains, and the aim of this work is to consolidate the knowledge of the ice evolution during the star formation process, and especially the influence of thermal reactions as a source of molecular complexity in the interstellar medium (ISM). In this study, we are interested in the thermal reactivity between two interstellar molecules, formaldehyde $\left(\mathrm{H}_{2} \mathrm{CO}\right)$, and methylamine $\left(\mathrm{CH}_{3} \mathrm{NH}_{2}\right)$ in water ice analogues. Formaldehyde absorption features in interstellar ices observed in young stellar objects (YSOs) in the 5.7-6 $\mu \mathrm{m}$ region (the so-called $\mathrm{C} 1$ component) indicate abundances around 6\% with respect to water (Boogert et al. 2008). Its formation in ice seems to be well understood and is explained by direct hydrogenation of $\mathrm{CO}$ on the grain surface (Hiraoka et al. 1994, 2002; Watanabe et al. 2004). Methylamine $\mathrm{CH}_{3} \mathrm{NH}_{2}$ is the simplest member of the primary alkylamine family and has been detected in gas phase by its $2_{02} \rightarrow 1_{10} \mathrm{~A}_{a}$ state transition in the direction of Sgr B2 and Ori A (Fourikis et al. 1974). In addition, results from the stardust mission support its presence in cometary cores (Elsila et al. 2009). Several pathways of formation either on grain surface or in gas phase have been proposed. Godfrey et al. (1973) suggested its formation on grain surface from the hydrogenation reactions starting on the $\mathrm{CN}$ radical (Eq. (1)). This mechanism has recently been experimentally validated starting from HCN (Theule et al. 2011),

$\mathrm{CN} \stackrel{\mathrm{H}}{\rightarrow} \mathrm{HCN} \stackrel{\mathrm{H}}{\rightarrow} \mathrm{CH}_{2} \mathrm{NH} \stackrel{\mathrm{H}}{\rightarrow} \mathrm{CH}_{3} \mathrm{NH}_{2}$.

Gardner \& McNesby (1982) and Ogura et al. (1989) proposed its formation from the UV photolysis of a gaseous mixture containing $\mathrm{CH}_{4}$ and $\mathrm{NH}_{3}$. Finally, Herbst (1985) proposed a gas phase methylamine formation from the methylium cation $\mathrm{CH}_{3}^{+}$and $\mathrm{NH}_{3}$. However, solid methylamine has never been detected in ice, so far. This could be due to its low abundance, but also to the difficulty to assign this compound from ices in infrared astronomical spectra. Works on ice analogues containing methylamine suggest that a plausible cause of its nonobservation in interstellar ices is its high reactivity at low temperature (Bossa et al. 2009a). Indeed, from a chemical point of view, $\mathrm{CH}_{3} \mathrm{NH}_{2}$ is a better nucleophile and base than ammonia. This molecule can quickly react at low temperature in interstellar ice analogues with acids, such as HNCO, HCN, and $\mathrm{HCOOH}$. In addition, methylamine reacts at low temperature with $\mathrm{CO}_{2}$, leading to the formation of methylammonium methylcarbamate $\left(\mathrm{CH}_{3} \mathrm{NH}_{3}^{+} \mathrm{CH}_{3} \mathrm{NHCOO}^{-}\right)$, which can be isomerised into glycine under UV irradiation (Bossa et al. 2009a). The measured activation barrier for this latter reaction, $3.7 \mathrm{~kJ} \mathrm{~mol}^{-1}$, is compatible with low temperature observed in molecular clouds 
(Bossa et al. 2009a). Among molecules observed in interstellar ices, formaldehyde is of prime interest, since thermally promoted formaldehyde reactions in presence of $\mathrm{NH}_{3}$ at low temperature have shown that they are an important source of organic molecules in astrophysical environments such as comets and interstellar ices (Schutte et al. 1993; Bossa et al. 2009b; Vinogradoff et al. 2011). The resulting products are the polymer of $\mathrm{H}_{2} \mathrm{CO}$, the polyoxymethylene (POM), and the aminomethanol $\left(\mathrm{NH}_{2} \mathrm{CH}_{2} \mathrm{OH}\right)$ (Schutte et al. 1993; Bossa et al. 2009b).

In this work, we demonstrate that methylamine and formaldehyde quickly react in water ices at low temperature to form $\mathrm{N}$-methylaminomethanol $\left(\mathrm{CH}_{3} \mathrm{NHCH}_{2} \mathrm{OH}\right)$. The measured activation energy of this reaction, $1.1 \mathrm{~kJ} \mathrm{~mol}^{-1}$, implies that this reaction can easily occur in interstellar ices, when the ices are gently warmed, as it is in YSOs, in photo-dissociation regions (PDRs), or in comets. Therefore, $\mathrm{CH}_{3} \mathrm{NHCH}_{2} \mathrm{OH}$ is likely to be found in these objects. This hypothesis is confirmed by numerical simulations, which show that the formation of N-methylaminomethanol is likely at low temperature. Isotopic experiments as well as photochemical studies have also been performed to better characterise ice evolution induced by heat and UV radiation in star-forming regions and cometary environments.

\section{Experimental and theoretical section}

Methylamine is commercially available as a $99.9995 \%$ pure gas from Air Liquide. Methylamine ${ }^{15} \mathrm{~N}$ is formed from methylamine $\left({ }^{15} \mathrm{~N}\right)-\mathrm{HCl}$ commercially available from Cambridge Isotope (98\%). The $\mathrm{H}_{2} \mathrm{O} / \mathrm{CH}_{3} \mathrm{NH}_{2} / \mathrm{H}_{2} \mathrm{CO}$ gas mixtures are prepared at room temperature into two mixing lines under primary vacuum. The first one for the $\mathrm{CH}_{3} \mathrm{NH}_{2}$ gas mixture and the second one for $\mathrm{H}_{2} \mathrm{CO}$ and $\mathrm{H}_{2} \mathrm{O}$, to prevent any gas phase reaction. They are then co-deposited with a chosen ratio onto a goldplated metal surface cooled to $20 \mathrm{~K}$ by a Model $21 \mathrm{CTI}$ cold head within a high vacuum chamber ( $\left.\mathrm{ca} 10^{-8} \mathrm{mbar}\right)$. The infrared spectra are recorded between 4000 and $650 \mathrm{~cm}^{-1}$ in the reflexion mode using a Fourier transform infrared spectrometer (FTIR). A typical spectrum has a $1 \mathrm{~cm}^{-1}$ resolution and is averaged over one hundred interferograms. The sample is warmed using a heating resistance, and the temperature is controlled using a Lakeshore Model 331 temperature controller. The mass spectra are recorded using an MKS quadrupole mass spectrometer as the products are being desorbed. The ionisation source is a $70 \mathrm{eV}$ impact electronic source, and the mass spectra are recorded between 1 and $80 \mathrm{amu}$. The UV radiations $(\lambda>120 \mathrm{~nm})$ are generated from a microwave discharge hydrogen flow lamp (Opthos instruments) separated from the vacuum chamber by a magnesium fluoride window. Lamp settings during irradiation are $P_{\mathrm{H}_{2}}=300 \times 10^{-3}$ mbar, microwave forward power $70 \%$, reflected power less than $10 \%$. The distance between the lamp and the ice sample is about $10 \mathrm{~cm}$. The flux has been calibrated with the actinometry method described by Cottin et al. (2003) using the photolysis of methanol. The flux of the hydrogen lamp is $2 \times 10^{15}$ photons $\mathrm{cm}^{-2} \mathrm{~s}^{-1}$. The concentration ratio of the different mixtures is first set before deposition using standard manometric techniques, and then derived from the infrared spectra by integrating vibrational bands to estimate the column density $N_{x}$ (molecule $\mathrm{cm}^{-2}$ ) of $\mathrm{CH}_{3} \mathrm{NH}_{2}$, and $\mathrm{H}_{2} \mathrm{CO}$ according to their band strengths $\mathcal{A}_{x}\left(\mathrm{~cm}\right.$ molecule $\left.{ }^{-1}\right)$ provided by the literature using $N_{x}=\frac{2.3 \times \int A_{v} \mathrm{~d} v}{2 \times \mathcal{A}_{x}}$. For $\mathrm{CH}_{3} \mathrm{NH}_{2}$, we used the band strength of the wagging mode at $889 \mathrm{~cm}^{-1}$ of $1.3 \times 10^{-17} \mathrm{~cm} \mathrm{molecule}^{-1}$ (Holtom et al. 2005), and for $\mathrm{H}_{2} \mathrm{CO}$, we used the values given

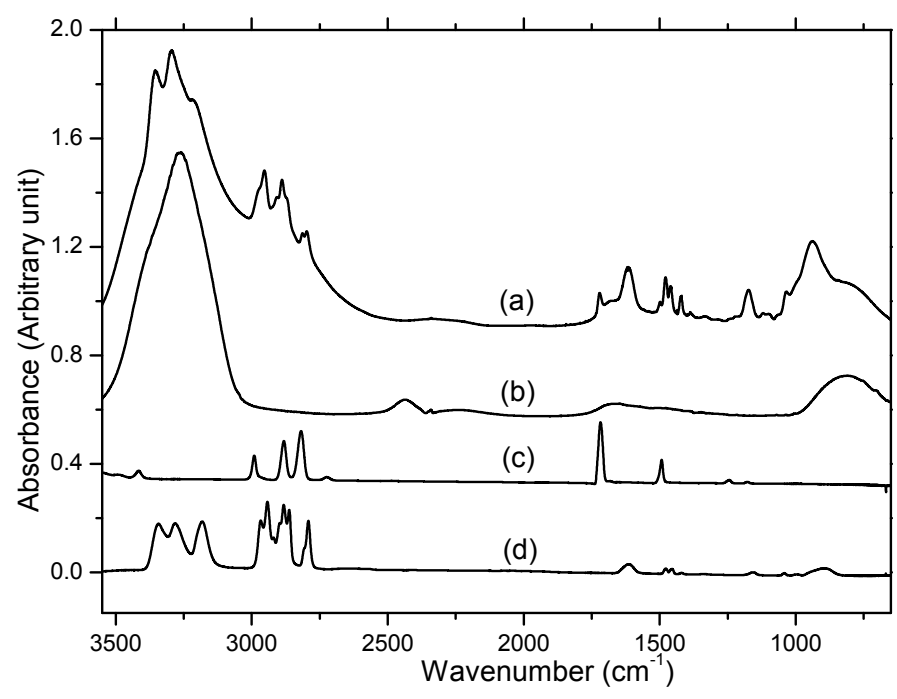

Fig. 1. FTIR spectrum of (a) $\mathrm{H}_{2} \mathrm{O} / \mathrm{H}_{2} \mathrm{CO} / \mathrm{CH}_{3} \mathrm{NH}_{2}=1 / 0.1 / 2$ ice mixture deposited at $30 \mathrm{~K}$; (b) pure $\mathrm{H}_{2} \mathrm{O}$ ice deposited at $30 \mathrm{~K}$; (c) pure $\mathrm{H}_{2} \mathrm{CO}$ ice deposited at $30 \mathrm{~K}$; (d) pure $\mathrm{CH}_{3} \mathrm{NH}_{2}$ deposited at $20 \mathrm{~K}$.

by Schutte et al. (1993): $9.6 \times 10^{-18} \mathrm{~cm}$ molecule ${ }^{-1}$ for the $\mathrm{C}=\mathrm{O}$ stretching mode at $1725.5 \mathrm{~cm}^{-1}$ and $4 \times 10^{-18} \mathrm{~cm} \mathrm{molecule}^{-1}$ for the $\mathrm{CH}_{2}$ scissoring mode at $1494 \mathrm{~cm}^{-1}$. The thickness of the deposited solid films, assuming a density of $0.92 \mathrm{~g} \mathrm{~cm}^{-3}$ for $\mathrm{H}_{2} \mathrm{O}$, is estimated to be around $0.1 \mu \mathrm{m}$. We also used the band integration strengths to monitor the decrease in the reacting infrared band intensities as reactants are consumed during the reaction, and to estimate how much of each product is formed. We estimated the N-methylaminomethanol band strengths assuming that all formaldehyde has been converted into it. Accordingly, knowing the amount of $\mathrm{N}$-methylaminomethanol and using the relation $N_{x}=\frac{2.3 \times \int A_{v} \mathrm{~d} v}{2 \times \mathcal{A}_{x}}$, we calculated the band strengths of the N-methylaminomethanol. We performed a vibrational analysis of the $\mathrm{N}$-methylaminomethanol $\left(\mathrm{CH}_{3} \mathrm{NHCH}_{2} \mathrm{OH}\right)$ to compute the harmonic vibrational frequencies for both the ${ }^{14} \mathrm{~N}$ and ${ }^{15} \mathrm{~N}$ isotopologues. Nevertheless, to simplify this analysis we did not take into account the effect of environment on the calculations. Calculations were performed using the Gaussian 98 package (Lee et al. 1988; Frisch et al. 1998) at the B3LYP/6-31G** level, which is known to supply reliable predictions of vibrational wavenumbers (Duvernay et al. 2004, 2007).

\section{Results}

\subsection{Warming of an $\mathrm{H}_{2} \mathrm{CO} / \mathrm{CH}_{3} \mathrm{NH}_{2}$ ice mixture: $\mathrm{N}$-methylaminomethanol formation}

Thermally promoted formaldehyde reactions at low temperature in $\mathrm{H}_{2} \mathrm{O} / \mathrm{NH}_{3} / \mathrm{H}_{2} \mathrm{CO}$ ices have been studied by Schutte et al. (1993) and Bossa et al. (2009b). These authors distinguished at least two different products: polyoxymethylene (POM) $\mathrm{HO}\left(\mathrm{CH}_{2} \mathrm{O}\right)_{n} \mathrm{H}$, the $\mathrm{H}_{2} \mathrm{CO}$ polymer, and aminomethanol $\left(\mathrm{NH}_{2} \mathrm{CH}_{2} \mathrm{OH}\right)$. The nature of the products and their relative abundances depend strongly on the initial composition of the initial ice mixture. Schutte et al. (1993) have shown that $\mathrm{NH}_{2} \mathrm{CH}_{2} \mathrm{OH}$ is the dominant product when $\mathrm{NH}_{3}$ is in excess with respect to $\mathrm{H}_{2} \mathrm{CO}$. We chose to adopt the same argument in working with an excess of methylamine to avoid formaldehyde polymerisation. Figure 1 displays the infrared spectrum of an ice mixture of $\mathrm{H}_{2} \mathrm{O} / \mathrm{H}_{2} \mathrm{CO} / \mathrm{CH}_{3} \mathrm{NH}_{2}(1 / 0.1 / 2)$ deposited at $30 \mathrm{~K}$ compared with the spectra of pure $\mathrm{H}_{2} \mathrm{O}, \mathrm{H}_{2} \mathrm{CO}$, and $\mathrm{CH}_{3} \mathrm{NH}_{2}$ 
V. Vinogradoff et al.: Reactivity in interstellar ice analogs

Table 1. Infrared absorption bands and vibrational assignments of $\mathrm{CH}_{3} \mathrm{NH}_{2}$ and $\mathrm{H}_{2} \mathrm{CO}$ in pure solids and in a water ice environment at $20 \mathrm{~K}$.

\begin{tabular}{|c|c|c|c|}
\hline \multirow{2}{*}{ Assignement } & \multicolumn{2}{|r|}{ Wavenumbers $\left(\mathrm{cm}^{-1}\right)$} & \multirow{2}{*}{$\begin{array}{c}\text { Band strength }\left(\mathrm{cm} \mathrm{molec}^{-1}\right) \\
\mathcal{A}\end{array}$} \\
\hline & Pure solid & $\mathrm{H}_{2} \mathrm{O}: \mathrm{CH}_{3} \mathrm{NH}_{2}: \mathrm{H}_{2} \mathrm{CO}(1 / 2 / 0.1)$ & \\
\hline \multicolumn{4}{|l|}{$\mathrm{CH}_{3} \mathrm{NH}_{2}{ }^{a}$} \\
\hline$v(\mathrm{NH})$ & 3334 & 3356 & \\
\hline$v(\mathrm{NH})$ & 3282 & 3295 & \\
\hline$v(\mathrm{NH})$ bonded & 3180 & 3200 & \\
\hline$v(\mathrm{CH})$ & 2943 & 2952 & \\
\hline$v(\mathrm{CH})$ & 2882 & 2889 & \\
\hline$v(\mathrm{CH})$ & 2792 & 2799 & \\
\hline$\delta\left(\mathrm{NH}_{2}\right)$ & 1615 & 1614 & $4.3 \times 10^{-18}$ \\
\hline$\delta\left(\mathrm{CH}_{3}\right)$ & 1477,1455 & 1477,1455 & \\
\hline$\delta\left(\mathrm{CH}_{3}\right)$ & 1425 & 1420 & \\
\hline$\rho\left(\mathrm{CH}_{3}\right)$ & 1157 & 1171 & $1.5 \times 10^{-18}$ \\
\hline$v(\mathrm{C}-\mathrm{N})$ & 1042 & 1038 & \\
\hline$\omega(\mathrm{NH})$ & 997,896 & 998,935 & $1.1 \times 10^{-17}$ \\
\hline \multicolumn{4}{|l|}{$\mathrm{H}_{2} \mathrm{CO}^{b}$} \\
\hline$v(\mathrm{CH})$ & 2998 & & \\
\hline$v(\mathrm{CH})$ & 2900 & & $2.2 \times 10^{-18}$ \\
\hline$\nu(\mathrm{C}=\mathrm{O})$ & 1715 & 1717 & $9.6 \times 10^{-18}$ \\
\hline$\delta(\mathrm{CH})$ & 1492 & 1497 & $4 \times 10^{-18}$ \\
\hline$\delta(\mathrm{CH})$ & 1247 & 1351 & $1.1 \times 10^{-18}$ \\
\hline
\end{tabular}

Notes. Vibration modes: stretching $(v)$, bending $(\delta)$, wagging $(\omega)$, and rocking $(\rho) .{ }^{(a)}$ Holtom et al. (2005); ${ }^{(b)}$ Schutte et al. (1993).

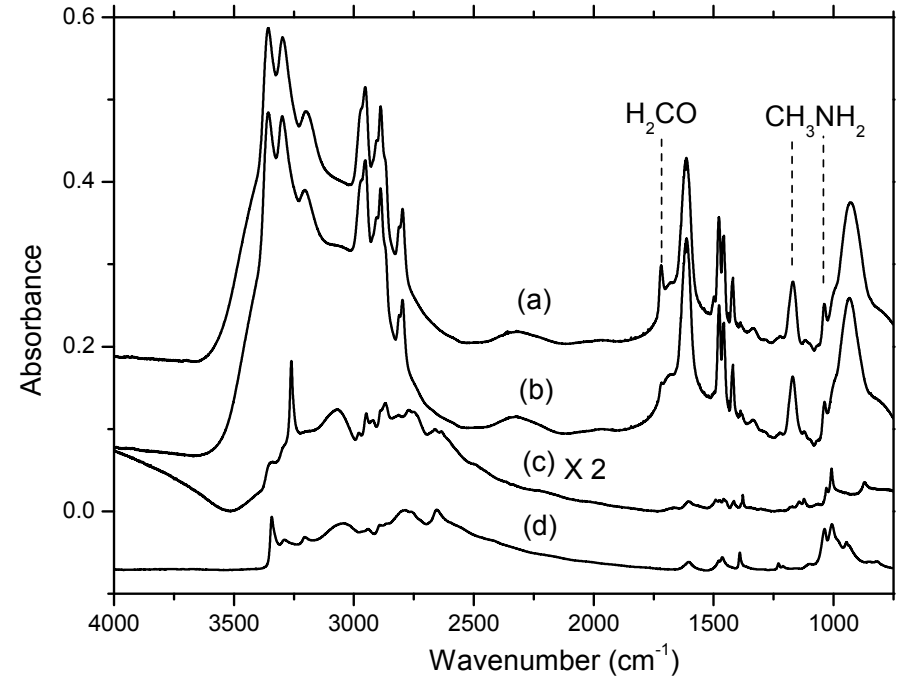

Fig. 2. FTIR spectra of (a) $\mathrm{H}_{2} \mathrm{O} / \mathrm{H}_{2} \mathrm{CO} / \mathrm{CH}_{3} \mathrm{NH}_{2}=1 / 0.1 / 2$ ice mixture deposited at $30 \mathrm{~K}$ and recorded at $30 \mathrm{~K}$; (b) recorded at $70 \mathrm{~K}$; (c) recorded at $190 \mathrm{~K}$; (d) pure aminomethanol $\left(\mathrm{NH}_{2} \mathrm{CH}_{2} \mathrm{OH}\right)$ recorded at $190 \mathrm{~K}$.

ices. The ice mixture spectrum is dominated by a strong and broad bands caused by the $\mathrm{OH}$ and $\mathrm{NH}$ stretching modes of $\mathrm{H}_{2} \mathrm{O}$ and $\mathrm{CH}_{3} \mathrm{NH}_{2}$. Formaldehyde is easily characterised from two characteristic bands located at 1715 and $1497 \mathrm{~cm}^{-1}$ caused by the $\mathrm{C}=\mathrm{O}$ stretching mode and $\mathrm{CH}$ bending modes. The infrared absorption bands observed in Fig. 1 can be assigned to initial species only, which indicates the lack of reactivity at $30 \mathrm{~K}$. These infrared absorption bands are listed in Table 1 along with their vibrational assignments and band strengths. This initial ice analogue was then warmed from $30 \mathrm{~K}$ to $240 \mathrm{~K}$ using different heating rates of $10,4,2,1$, and $0.5 \mathrm{~K} \mathrm{~min}^{-1}$.

Figure 2 displays the infrared spectrum of an ice mixture of $\mathrm{H}_{2} \mathrm{O} / \mathrm{H}_{2} \mathrm{CO} / \mathrm{CH}_{3} \mathrm{NH}_{2}(1 / 0.1 / 2)$ deposited at $30 \mathrm{~K}$ and then warmed at $4 \mathrm{~K} \mathrm{~min}^{-1}$. From $45 \mathrm{~K}$, the bands caused by formaldehyde start to decrease and fully disappear at $70 \mathrm{~K}$ (Fig. 2b). This range of temperature is lower than expected for formaldehyde sublimation, which in our experimental conditions is observed between 100 and $110 \mathrm{~K}$. At $190 \mathrm{~K}$, it remains on the substrate the reaction product (Fig. 2c). Thus the disappearance of $\mathrm{H}_{2} \mathrm{CO}$ can only be explained by reactivity. Changing the heating rate from 10 to $0.5 \mathrm{~K} \mathrm{~min}^{-1}$ does not alter the reactivity. Nevertheless, heating rates in the ISM are expected to be lower than those usually used in laboratory. Heating rates as low as this cannot be investigated in the laboratory, so it is hard to predict in which way they will affect the chemistry. The thermal reactivity of $\mathrm{H}_{2} \mathrm{CO}$ in ice with $\mathrm{NH}_{3}$ has previously been investigated experimentally and theoretically (Schutte et al. 1993; Bossa et al. 2009b; Chen \& Woon 2011; Rimola et al. 2010). This reaction leads to the formation of the aminoalcohol $\mathrm{NH}_{2} \mathrm{CH}_{2} \mathrm{OH}$, which occurs in a low barrier nucleophilic addition between $\mathrm{NH}_{3}$ and $\mathrm{H}_{2} \mathrm{CO}$. The infrared spectrum of the observed product is consistent with an aminoalcohol structure, which in this experiment should be the $\mathrm{N}$-methylaminomethanol $\left(\mathrm{CH}_{3} \mathrm{NHCH}_{2} \mathrm{OH}\right)$ (Figs. 2c, and d). Indeed, the spectrum is dominated by a strong band in the $\mathrm{NH}$ stretching region at $3260 \mathrm{~cm}^{-1}$, and in the $\mathrm{C}-\mathrm{O}, \mathrm{C}-\mathrm{N}$ stretching region (Fig. 3). To confirm the N-methylaminomethanol formation, we performed an isotopic substitution experiment using ${ }^{15} \mathrm{~N}$ methylamine, and compared these results with those obtained from our quantum calculation using the B3LYP $6-311 \mathrm{G}++(2 \mathrm{~d}, 2 \mathrm{p})$ basis set. The theoretical and experimental frequencies for ${ }^{14} \mathrm{~N}$-methylaminomethanol are listed in Table 2 along with theoretical and experimental frequency shifts between ${ }^{14} \mathrm{~N}$ and ${ }^{15} \mathrm{~N}$ isotopologues. Although harmonic calculations overestimate frequencies corresponding to $\mathrm{X}-\mathrm{H}$ stretching modes (Table 2), we observe a good agreement between the experimental and calculated frequencies of ${ }^{14} \mathrm{~N}$-methylaminomethanol (Table 2, Fig. 3), especially at frequencies lower than $1600 \mathrm{~cm}^{-1}$. We also compared experimental frequency shifts between ${ }^{14} \mathrm{~N}$ and ${ }^{15} \mathrm{~N}$ isotopologues with theoretical values. Calculated frequency shifts are small (smaller than $15 \mathrm{~cm}^{-1}$ ). The largest 
Table 2. Experimental and theoretical frequencies (in $\mathrm{cm}^{-1}$ ) and integrated band strengths ( $\mathrm{cm}$ molecule ${ }^{-1}$ ) of pure $\mathrm{CH}_{3}^{14} \mathrm{NHCH}_{2} \mathrm{OH}$ and $\mathrm{CH}_{3}^{15} \mathrm{NHCH}_{2} \mathrm{OH}$.

\begin{tabular}{|c|c|c|c|c|c|}
\hline \multirow[b]{2}{*}{ Mode } & \multicolumn{3}{|c|}{ Experimental values } & \multicolumn{2}{|c|}{ Theoretical B3LYP/6-31G** } \\
\hline & $\begin{array}{c}\text { Position }{ }^{14} \mathrm{~N} \\
\left(\mathrm{~cm}^{-1}\right)\end{array}$ & $\begin{array}{c}\text { band strength } \\
(\mathrm{cm} \mathrm{molec} \\
\left.{ }^{-1}\right)\end{array}$ & $\begin{array}{c}\Delta v\left({ }^{14} \mathrm{~N}-{ }^{15} \mathrm{~N}\right)^{b} \\
\left(\mathrm{~cm}^{-1}\right)\end{array}$ & $\begin{array}{c}\text { intensities } \\
(\%)\end{array}$ & $\begin{array}{c}\Delta v\left({ }^{14} \mathrm{~N}-{ }^{15} \mathrm{~N}\right)^{b} \\
\left(\mathrm{~cm}^{-1}\right)\end{array}$ \\
\hline$v(\mathrm{OH})$ & 3072 & $1.7 \times 10^{-17}$ & 5 & 7 & 0 \\
\hline$v(\mathrm{NH})$ & 3260 & $1.4 \times 10^{-17}$ & 7 & $<1$ & 8 \\
\hline$v\left(\mathrm{CH}_{3}\right)$ & 2981 & & 0 & 10 & 0 \\
\hline$v\left(\mathrm{CH}_{3}\right)$ & 2949 & & -1 & 28 & 0 \\
\hline$v\left(\mathrm{CH}_{3}\right)$ & 2888 & & 0 & 65 & 0 \\
\hline$v(\mathrm{CH})$ & 2868 & & -1 & 100 & 0 \\
\hline$\delta(\mathrm{CH})$ & 1490 & & 0 & 3 & 0 \\
\hline$\delta(\mathrm{CH})$ & 1475 & & 0 & 3 & 0 \\
\hline$\delta(\mathrm{CH})$ & 1455 & & 0 & 7 & 1 \\
\hline$\delta(\mathrm{CH})+\delta(\mathrm{NH})$ & 1445 & & 0 & 11 & 2 \\
\hline$\delta(\mathrm{CH})+\delta(\mathrm{NH})$ & 1414 & $6 \times 10^{-19}$ & 0 & 17 & 4 \\
\hline$\delta(\mathrm{OH})+\delta(\mathrm{CH})$ & 1376 & $7 \times 10^{-19}$ & 2 & 42 & 0 \\
\hline$\delta(\mathrm{OH})+\delta(\mathrm{CH})$ & 1305 & $1.4 \times 10^{-19}$ & 0 & 3 & 0 \\
\hline$\rho(\mathrm{CH})$ & 1225 & & 11 & 10 & 6 \\
\hline$v(\mathrm{C}-\mathrm{O})$ & 1146 & $3.5 \times 10^{-19}$ & 6 & 3 & 4 \\
\hline$v(\mathrm{C}-\mathrm{N})$ & 1120 & $4.7 \times 10^{-19}$ & 11 & 60 & 13 \\
\hline$v(\mathrm{C}-\mathrm{N})+v(\mathrm{C}-\mathrm{O})$ & 1063 & & 0 & 25 & 3 \\
\hline$v(\mathrm{C}-\mathrm{O})$ & 1031 & $4.3 \times 10^{-19}$ & 3 & 77 & 4 \\
\hline$\delta(\mathrm{OH})$ & 1009 & $2.3 \times 10^{-18}$ & 1 & 14 & 1 \\
\hline$v(\mathrm{CN})$ & 870 & $1.6 \times 10^{-18}$ & 5 & 10 & 6 \\
\hline
\end{tabular}

Notes. Vibration mode: stretching $(v)$, bending $(\delta)$, rocking $(\rho){ }^{(a)}$ This work. See experimental part for details. ${ }^{(b)}$ Isotopic frequency shifts between the ${ }^{14} \mathrm{~N}$ and ${ }^{15} \mathrm{~N}$ isotopologues $\mathrm{CH}_{3} \mathrm{NHCH}_{2} \mathrm{OH}\left(\Delta v\left({ }^{14} \mathrm{~N}-{ }^{15} \mathrm{~N}\right)\right)$ are compared with theoretical frequency shifts. Theoretical calculations are performed using the B3LYP method with the $6-31 \mathrm{G}^{* *}$ basis set. The theoretical intensities are normalized.

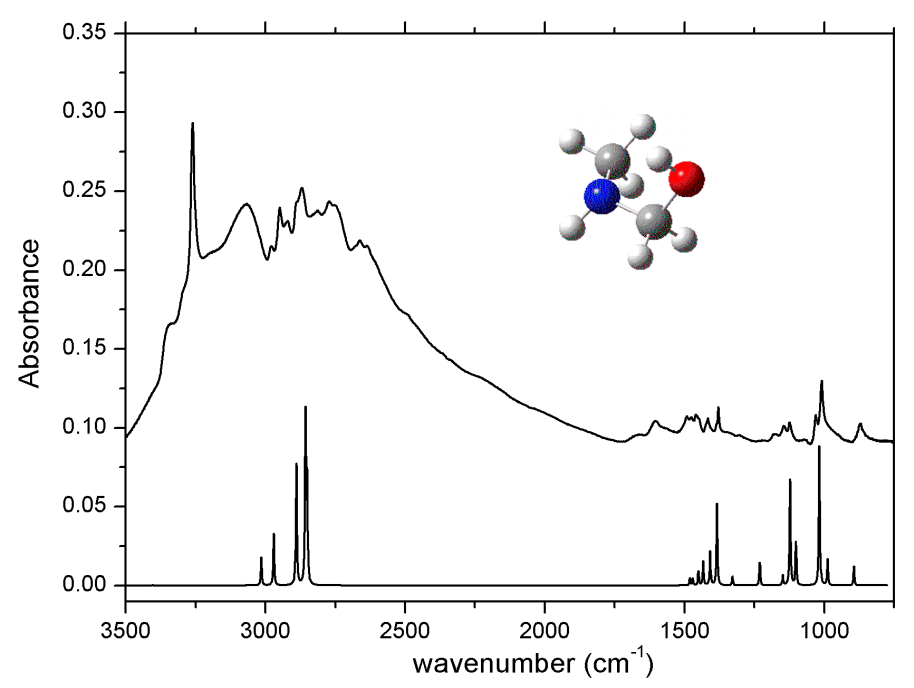

Fig. 3. FTIR spectrum of pure $\mathrm{CH}_{3} \mathrm{NHCH}_{2} \mathrm{OH}$ formed from the warming of an $\mathrm{H}_{2} \mathrm{O} / \mathrm{H}_{2} \mathrm{CO} / \mathrm{CH}_{3} \mathrm{NH}_{2}$ ice mixture compared with the corresponding B3LYP infrared spectrum.

calculated shift of $13 \mathrm{~cm}^{-1}$ is for the $\mathrm{C}-\mathrm{N}$ stretching mode, which agrees well with the observed experimental shift of $11 \mathrm{~cm}^{-1}$ (Table 2). The same agreement is also observed for others modes. For example, the calculated isotopic shift for the $\mathrm{NH}$ stretching mode is $8 \mathrm{~cm}^{-1}$, while we experimentally observed $7 \mathrm{~cm}^{-1}$.

The $\mathrm{CH}_{3} \mathrm{NHCH}_{2} \mathrm{OH}$ formation is also confirmed by mass spectrometry as shown in Fig. 4. A clear peak at $m / z 61$ is observed when the ${ }^{14} \mathrm{~N}$-methylaminomethanol sublimates from the substrate around $210 \mathrm{~K}$. This peak is assigned to the

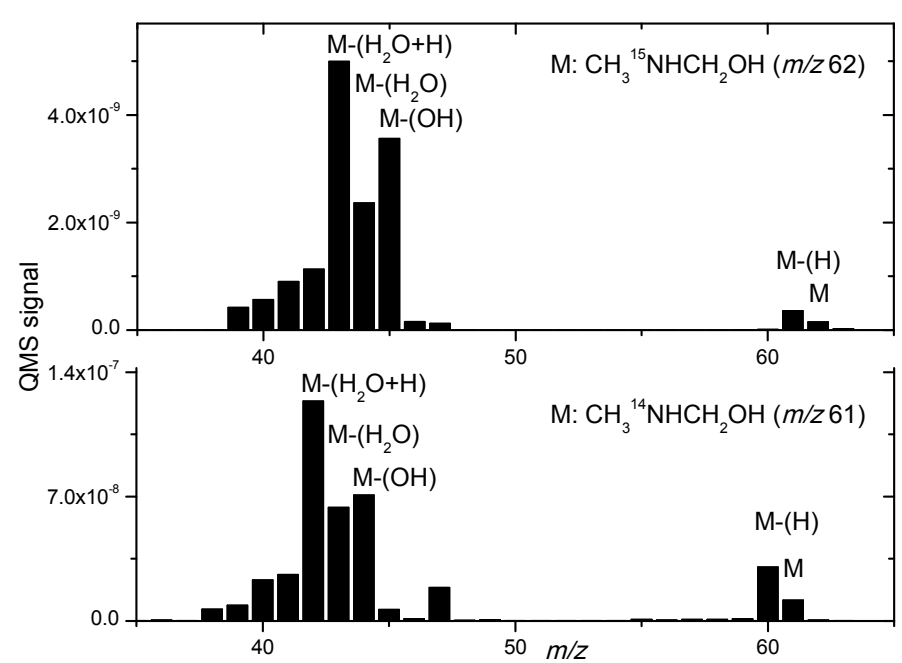

Fig. 4. Mass spectrum of $\mathrm{CH}_{3} \mathrm{NHCH}_{2} \mathrm{OH}{ }^{14} \mathrm{~N}$ and ${ }^{15} \mathrm{~N}$ recorded at $210 \mathrm{~K}$.

$\mathrm{CH}_{3} \mathrm{NHCH}_{2} \mathrm{OH}$ molecular ion and is labelled $\mathrm{M}$ in Fig. 4. In addition, the peak at $\mathrm{m} / \mathrm{z} 43$ (Fig. 4) corresponding to the loss of $\mathrm{H}_{2} \mathrm{O}(\mathrm{M}-18)$ is consistent with a molecule-bearing $\mathrm{OH}$ group. The mass spectrum of the ${ }^{15} \mathrm{~N}$ isotopologue is similar, although most of the peaks are shifted forward by 1 mass unity due to the isotopic substitution (Fig. 4), which confirms the previous assignments. The ice composition we used to form and characterise the N-methylaminomethanol is not astrophysically relevant since we worked with an excess of methylamine to avoid the formaldehyde polymerisation. To check if the N-methylaminomethanol formation is still possible in a more realistic ice, we investigated the warming of an ice mixture 


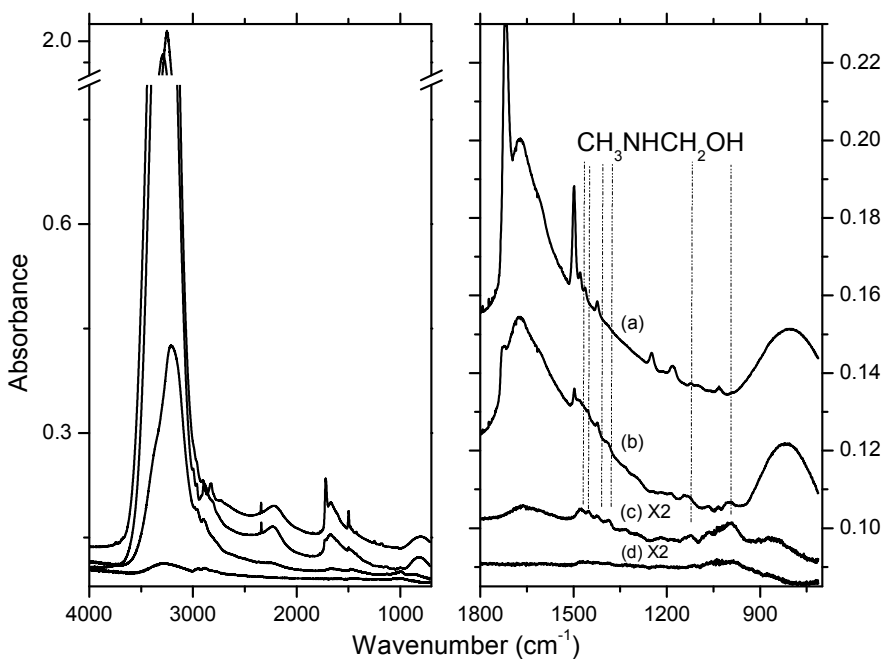

Fig. 5. FTIR spectra of (a) $\mathrm{H}_{2} \mathrm{O} / \mathrm{H}_{2} \mathrm{CO} / \mathrm{CH}_{3} \mathrm{NH}_{2}=1 / 0.1 / 0.05$ ice mixture deposited at $30 \mathrm{~K}$ and recorded at $30 \mathrm{~K}$; (b) recorded at $125 \mathrm{~K}$; (c) recorded at $185 \mathrm{~K}$; (d) recorded at $200 \mathrm{~K}$.

containing $\mathrm{H}_{2} \mathrm{O} / \mathrm{H}_{2} \mathrm{CO} / \mathrm{CH}_{3} \mathrm{NH}_{2}=1 / 0.1 / 0.05$. Figure 5 shows the thermal evolution of this ice mixture. The infrared spectrum recorded at $30 \mathrm{~K}$ after deposition is dominated by the strong infrared band of water at $3200 \mathrm{~cm}^{-1}$, while the infrared features of formaldehyde and methylamine are weak due to their low abundances in the ice mixture (Fig. 5). The ice mixture was then warmed at $4 \mathrm{~K} \mathrm{~min}^{-1}$. At $125 \mathrm{~K}$, both formaldehyde and methylamine have been consumed while the bands of N-methylaminomethanol are observed at 1481, 1454, 1423, $1388,1208,1143,1064,1032$, and $1004 \mathrm{~cm}^{-1}$. The position of the bands slightly differs from their positions observed for the pure solid (Table 2) because of the large amount of water. Hydrogen interaction between water and the $\mathrm{N}$-methylaminomethanol could be at the origin of these slight frequency shifts. At $185 \mathrm{~K}$, while the water is sublimating from the substrate, we notice a decrease of the infrared features of the $\mathrm{N}$-methylaminomethanol, indicating that a part of the product is driven away by the water desorption. This is confirmed by the infrared spectrum recorded at $200 \mathrm{~K}$. At this temperature, only a trace of the $\mathrm{N}$-methylaminomethanol remains on the substrate. This is an important result from an astrophysical point of view. Indeed, the formation of the N-methylaminomethanol, from the heating of a realistic ice analogue, is still possible and the majority of the thermal product is released in the gas phase during the water desorption, allowing its detection by radio astronomy.

\subsection{Rate of $\mathrm{CH}_{3} \mathrm{NHCH} \mathrm{H}_{2} \mathrm{OH}$ formation}

We measured the $\mathrm{CH}_{3} \mathrm{NHCH}_{2} \mathrm{OH}$ formation rate in a $\mathrm{H}_{2} \mathrm{O} / \mathrm{CH}_{3} \mathrm{NH}_{2} / \mathrm{H}_{2} \mathrm{CO}$ ice mixture in an $1 / 2 / 0.1$ concentration ratio. We chose to work with a methylamine excess to avoid any formaldehyde polymerisation and to ensure a first-order decay for the formaldehyde. In a first approximation we can state that the methylamine concentration in the ice is constant during the ice warming. The ice mixture was deposited at $19 \mathrm{~K}$ and then warmed at $4 \mathrm{~K} \mathrm{~min}^{-1}$. During the warming, we followed the evolution of the formaldehyde using its band located at $1715 \mathrm{~cm}^{-1}$ $\left(\mathcal{A}=9.6 \times 10^{-18} \mathrm{~cm}\right.$ molecule $\left.{ }^{-1}\right)$. This thermal evolution is displayed in Fig. 6. Experimental data were fitted using Eq. (2). In this equation, $T$ is the temperature $(\mathrm{K}), v_{0}$ the pre-exponential factor $\left(\mathrm{s}^{-1}\right), E_{\mathrm{a}}$ the activation energy $\left(\mathrm{kJ} \mathrm{mol}^{-1}\right)$, and $\beta$ the

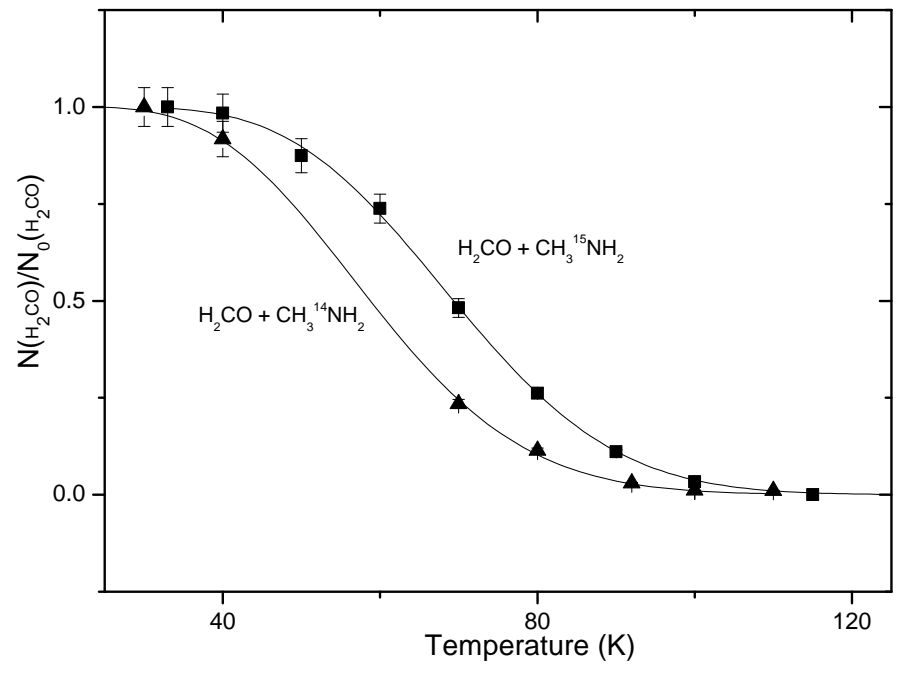

Fig. 6. Formaldehyde thermal evolution as a function of temperature in water ice containing $\mathrm{CH}_{3} \mathrm{NH}_{2}{ }^{14} \mathrm{~N}$ (triangle), and ${ }^{15} \mathrm{~N}$ (square) $\left(\mathrm{H}_{2} \mathrm{O} / \mathrm{CH}_{3} \mathrm{NH}_{2} / \mathrm{CH}_{2} \mathrm{O}=1 / 2 / 0.1\right)$. The rate coefficients are given in the form $k=v_{0} \exp (-E / R T)$, where $T$ is the ice temperature $(\mathrm{K}), v_{0}$ the pre-exponential factor $\left(\mathrm{s}^{-1}\right)$, and $E$ the activation energy $\left(\mathrm{J} \mathrm{mol}^{-1}\right)$. The corresponding rate coefficients are $k_{14 \mathrm{~N}}=1.5 \pm 0.1 \times 10^{-2} \exp (-1100 \pm$ $50 / R T)$ and $k_{15 \mathrm{~N}}=2.6 \pm 0.3 \times 10^{-2} \exp (-1800 \pm 80 / R T)$.

temperature ramp $\left(\mathrm{K} \min ^{-1}\right)$. We integrated the formaldehyde variation over the time and then substituted the time by the temperature according to the relation $T=T_{0}+\beta t$. We finally obtained a relation between the amount of formaldehyde as a function of temperature (Eq. (2)),

$$
\left\{\begin{array}{l}
\frac{\mathrm{d}\left[\mathrm{H}_{2} \mathrm{CO}\right]_{t}}{\mathrm{~d} t}=-k_{T}\left[\mathrm{H}_{2} \mathrm{CO}\right]_{t} \\
T=T_{0}+\beta t \text { and } k_{T}=v_{0} \mathrm{e}^{-\frac{E_{\mathrm{a}}}{R T}} \\
{\left[\mathrm{H}_{2} \mathrm{CO}\right]_{T}=\left[\mathrm{H}_{2} \mathrm{CO}\right]_{0} \mathrm{e}^{\frac{v_{0}\left(T_{0}-T\right)}{\beta}} \mathrm{e}^{-\frac{E_{\mathrm{a}}}{R T}}}
\end{array}\right.
$$

The derivated activation energy of $1.1 \pm .05 \mathrm{~kJ} \mathrm{~mol}^{-1}$ (i.e. $133 \mathrm{~K}$ ) is lower than the one obtained for the aminomethanol (4.5 kJ mol $^{-1}$ or $541 \mathrm{~K}$ ) (Bossa et al. 2009b). This is not surprising since methylamine is a better nucleophile than ammonia. Moreover, a barrier this low is compatible with the low temperature observed in interstellar ices, meaning that the addition of methylamine on formaldehyde is likely in interstellar grains. We also investigated the influence of isotopic substitution on the reaction rate. We used the same experimental procedure as previously on an ice mixture containing $\mathrm{H}_{2} \mathrm{O} / \mathrm{CH}_{3}^{15} \mathrm{NH}_{2} / \mathrm{CH}_{2} \mathrm{O}$ in a 1/2/0.1 concentration ratio. This ice mixture was deposited at $19 \mathrm{~K}$ and then warmed at $4 \mathrm{~K} \mathrm{~min}^{-1}$ as for the ${ }^{14} \mathrm{~N}$ experiment. The corresponding thermal evolution is displayed in Fig. 6. The time evolution of formaldehyde was then fitted with Eq. (2). The derived activation energy is in this case, $1.8 \pm .08 \mathrm{~kJ} \mathrm{~mol}^{-1}$ (i.e. $217 \mathrm{~K}$ ). The isotopic substitution modifies the reaction rate (as seen in Fig. 6) and the activation barrier. This is consistent with a primary isotopic effect, since the bonds that are formed during the reaction involves the nitrogen atom. However, the difference between the measured barrier for the ${ }^{14} \mathrm{~N}$ and ${ }^{15} \mathrm{~N}$ is bigger than the value we would expect for nitrogen substitution. This could be due to the mechanism of $\mathrm{N}$-methylaminomethanol formation in ice at low temperature. Indeed, the measured activation barriers are effective barriers that include diffusion processes of the reactants, nucleophilic addition (i.e. attack of the methylamine on the formaldehyde), and finally the hydrogen transfer from the nitrogen to the oxygen of the $\mathrm{N}$-methylaminomethanol. All these 


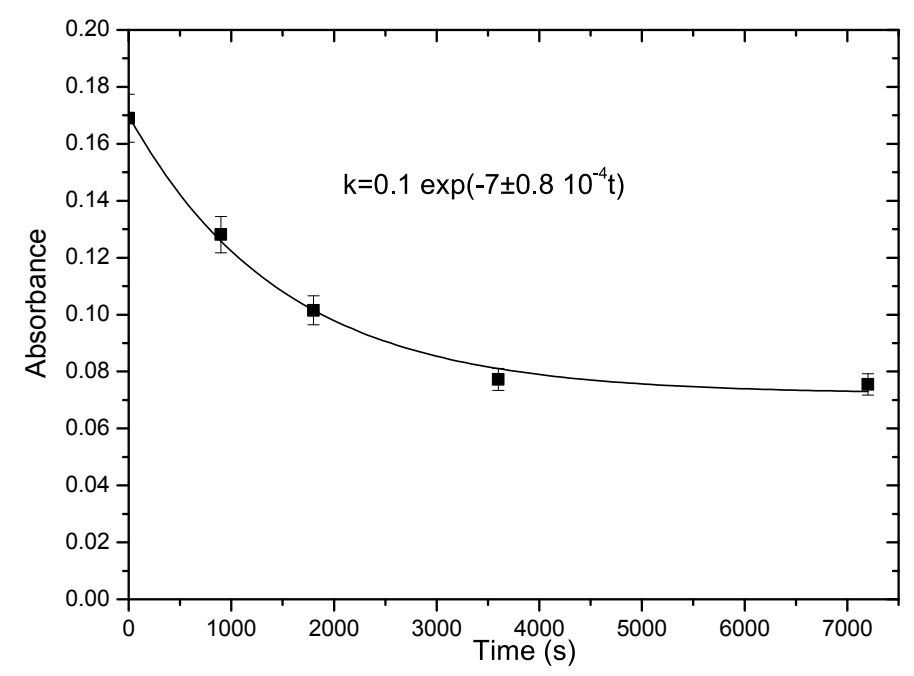

Fig. 7. Absorbance of $\mathrm{CH}_{3} \mathrm{NHCH}_{2} \mathrm{OH}$ as a function of UV irradiation time. Experimental data are fitted against a first-order decay.

processes could be sensitive to the isotopic substitution, leading to an isotopic kinetic effect stronger than it would appear in liquid phase at room temperature where diffusion and hydrogen transfers are not necessary the limiting rate of nucleophilic addition reaction.

\subsection{Photolysis of $\mathrm{CH}_{3} \mathrm{NHCH}_{2} \mathrm{OH}$}

As already mentioned in the introduction, interstellar ices in a star-forming region or in pre-cometary ices are submitted to various physical processes such as UV irradiation. Therefore, we investigated the UV degradation of the $\mathrm{N}$-methylaminomethanol. We first formed $\mathrm{CH}_{3} \mathrm{NHCH}_{2} \mathrm{OH}$ as described above. We then desorbed the starting materials $\left(\mathrm{H}_{2} \mathrm{O}, \mathrm{H}_{2} \mathrm{CO}\right.$, and $\left.\mathrm{CH}_{3} \mathrm{NH}_{2}\right)$ at $180 \mathrm{~K}$ to obtain pure $\mathrm{CH}_{3} \mathrm{NHCH}_{2} \mathrm{OH}$. We then irradiated it at $20 \mathrm{~K}$ with a UV hydrogen lamp and followed its photolysis by infrared spectroscopy as displayed in Fig. 7. The UV flux is estimated to be $2 \times 10^{15}$ photons $\mathrm{cm}^{-2} \mathrm{~s}^{-1}$. After $120 \mathrm{~min}$ of UV irradiation, $60 \%$ of $\mathrm{CH}_{3} \mathrm{NHCH}_{2} \mathrm{OH}$ was consumed, as shown in Fig. 7, and its decay was fitted by a first-order kinetic rate. The corresponding kinetic constant is found to be around $7 \pm 0.8 \times 10^{-4} \mathrm{~s}^{-1}$. With our flux of photons, the photodestruction cross-section can be estimated to be $\sigma_{\text {photo }}=3 \pm$ $0.4 \times 10^{-19}$ photon $^{-1} \mathrm{~cm}^{2}$. This photo-destruction cross-section refers at least to two different processes: photo-dissociation (i.e. bond-breaking) and photo-desorption (Fayolle et al. 2011, and references therein). However, in our vacuum condition, it is not possible to separate those two processes.

In addition to the infrared signatures of $\mathrm{CH}_{3} \mathrm{NHCH}_{2} \mathrm{OH}$ (see Fig. 8), the irradiated sample displays through new bands at $1670 \mathrm{~cm}^{-1}$ the formation of an amide, which could be the Nmethylformamide $\mathrm{CH}_{3} \mathrm{NHCHO}$ (Shin et al. 2006), as shown in Fig. 8. After irradiating $\mathrm{N}$-methylaminomethanol at $10 \mathrm{~K}$, the sample was warmed to $250 \mathrm{~K}$ and the desorption of the photo-product was monitored by mass spectrometry (Fig. 9). At $220 \mathrm{~K}$, a clear peak is observed at $\mathrm{m} / \mathrm{z}$ 59, corresponding to the molecular ion of $\mathrm{N}$-methylformamide. This peak is not present when $\mathrm{CH}_{3} \mathrm{NHCH}_{2} \mathrm{OH}$ is not irradiated. It has been noted that UV irradiation induces a modification of temperature desorption through changes in the ice structure induced by photons (Fig. 9). The N-methylformamide formation from

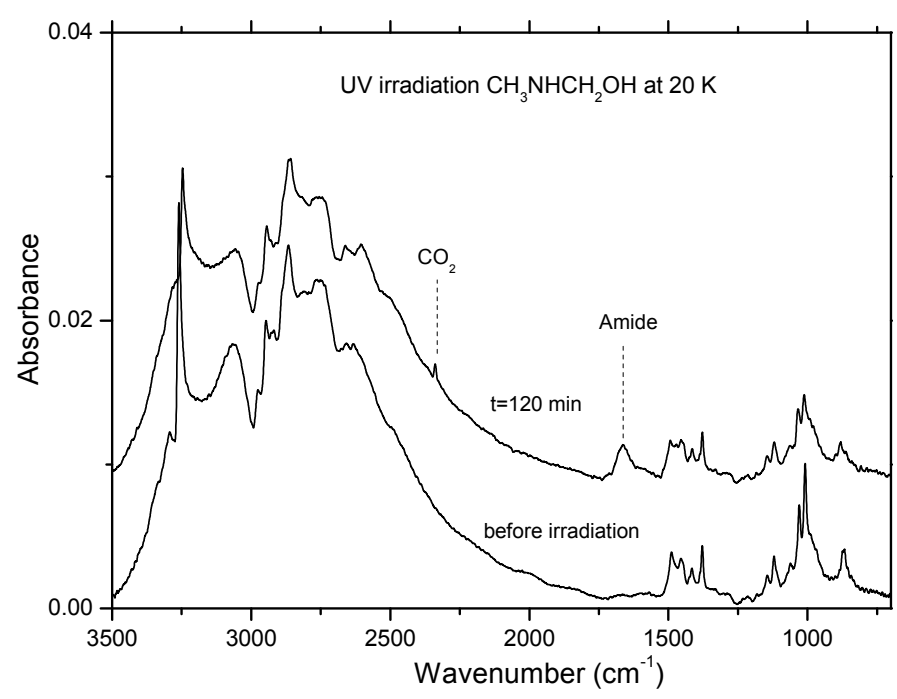

Fig. 8. Infrared spectra of the UV photolysis of pure $\mathrm{CH}_{3} \mathrm{NHCH}_{2} \mathrm{OH}$ ${ }^{14} \mathrm{~N}$ at $20 \mathrm{~K}$.

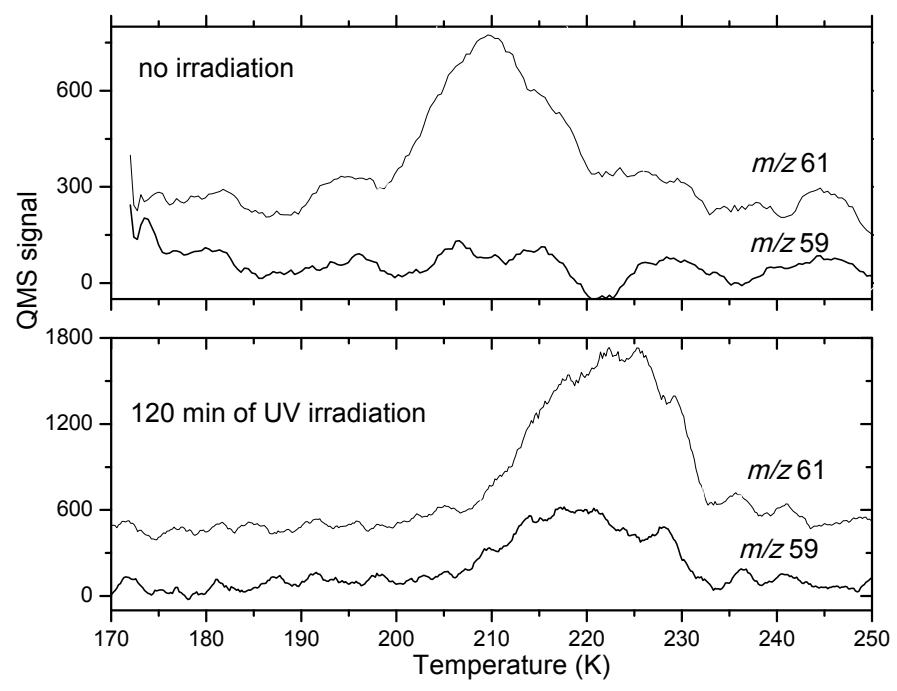

Fig. 9. Temperature-programmed desorption of pure N-methylaminomethanol with and without UV irradiation. The $\mathrm{m} / \mathrm{z}, 61$ signal refers to the $\mathrm{N}$-methylaminomethanol while the $\mathrm{m} / \mathrm{z}, 59$ signal refers to the photo-product: the $\mathrm{N}$-methylformamide.

$\mathrm{N}$-methylaminomethanol may be the result of a dehydrogenation process as follows:

$$
\mathrm{CH}_{3} \mathrm{NHCH}_{2} \mathrm{OH}+\mathrm{h} v \rightarrow \mathrm{CH}_{3} \mathrm{NHCHO}+\mathrm{H}_{2} \text {. }
$$

The same dehydrogenation mechanism has been observed in the UV photolysis of methanol and aminomethanol that give formaldehyde and formamide, respectively (Öberg et al. 2009; Bossa et al. 2009b). The direct production of $\mathrm{N}$-methylformamide from the photolysis of our product is an additional evidence of the $\mathrm{N}$-methylaminomethanol formation.

\section{Astrophysical implications}

We experimentally demonstrated that formaldehyde and methylamine quickly react in laboratory conditions to form the $\mathrm{N}$-methylaminomethanol. To know if this reaction could be likely in more astrophysical conditions in terms of temperature, 
Table 3. Parameters for thermal reactions, desorptions, and photo-destruction.

\begin{tabular}{lccccc}
\hline \hline Chemical reactions & Reaction rate ${ }^{a}$ & $v_{0}\left(\mathrm{~s}^{-1}\right)$ & $v_{0}(\mathrm{dif})\left(\mathrm{s}^{-1}\right)$ & $E(\mathrm{~K})$ & Ref. \\
\hline $\mathrm{H}_{2} \mathrm{CO}+\mathrm{NH}_{3} \rightarrow \mathrm{NH}_{2} \mathrm{CH}_{2} \mathrm{OH}$ & $k_{1}$ & $0.5 \times 10^{-2}$ & $3.3 \times 10^{-9}$ & 541 & (Bossa et al. 2009b) \\
$\mathrm{H}_{2} \mathrm{CO}+\mathrm{CH}_{3} \mathrm{NH}_{2} \rightarrow \mathrm{CH}_{3} \mathrm{HNCH}_{2} \mathrm{OH}$ & $k_{2}$ & $1.5 \times 10^{-2}$ & $3.3 \times 10^{-9}$ & 133 & This work \\
$\mathrm{CO}_{2}+2 \mathrm{CH}_{3} \mathrm{NH}_{2} \rightarrow \mathrm{CH}_{3} \mathrm{NH}_{2}^{+} \mathrm{CH}_{3} \mathrm{NHCOO}^{-}$ & $k_{13}$ & $2 \times 10^{-2}$ & $3.3 \times 10^{-9}$ & 445 & (Bossa et al. 2009a) \\
\hline Species & Desorption rate & $v_{0}\left(\mathrm{~s}^{-1}\right)$ & $E(\mathrm{~K})$ & Ref. \\
\hline $\mathrm{NH}_{3}$ & $k_{5}$ & $3 \times 10^{12}$ & 3008 & (Sandford et al. 1993) \\
$\mathrm{H}_{2} \mathrm{CO}$ & $k_{4}$ & $1 \times 10^{13}$ & 3250 & (Theule et al. 2012) \\
$\mathrm{CH}_{3} \mathrm{NH}_{2}$ & $k_{8}$ & $3 \times 10^{12}$ & 3008 & (c) \\
$\mathrm{NH}_{2} \mathrm{CH}_{2} \mathrm{OH}$ & $k_{9}$ & $3 \times 10^{12}$ & 6980 & (Bossa et al. 2009b) \\
$\mathrm{CH}_{3} \mathrm{HNCH} \mathrm{HH}_{2} \mathrm{OH}$ & $k_{11}$ & $3 \times 10^{12}$ & 6980 & (Bossa et al. 2009b) \\
\hline $\mathrm{Species}$ & Photo-destruction rate $^{b}$ & $\sigma\left(\mathrm{photon} \mathrm{cm}^{2}\right)$ & Ref. \\
\hline $\mathrm{CH}_{3} \mathrm{HNCH} \mathrm{OH}$ & $k_{12}$ & $3 \times 10^{-19}$ & this work \\
$\mathrm{NH}_{3}$ & $k_{6}$ & $3.2 \times 10^{-20}$ & (Cottin et al. 2003) \\
$\mathrm{CH}_{3} \mathrm{NH}_{2}$ & $k_{7}$ & $3.2 \times 10^{-20}$ & (Cottin et al. 2003) \\
$\mathrm{H}_{2} \mathrm{CO}$ & $k_{3}$ & $1.0 \times 10^{-19}$ & (Woodall et al. 2007) \\
$\mathrm{NH}_{2} \mathrm{CH} \mathrm{HH}_{2} \mathrm{OH}$ & $k_{10}$ & $4.5 \times 10^{-19}$ & (Duvernay et al. 2010) \\
$\mathrm{CO}_{2}$ & $k_{14}$ & $3.8 \times 10^{-19}$ & (Cottin et al. 2003) \\
\hline
\end{tabular}

Notes. ${ }^{(a)}$ The rate coefficients are given in the form $k=v_{0} \exp (-E / T)$, where $T$ is the ice temperature, $v_{0}$ the pre-exponential factor, and $E$ the activation energy (reaction or desorption). The diffusion factor $\left(v_{0}(\right.$ dif $\left.)\right)$ is obtained using the method developed by Hasegawa et al. (1992). (b) Photo-destruction rates are written as $k=\sigma f$, where $\sigma$ represents the photo-destruction cross-section and $f$ the interstellar ultraviolet radiation field. ${ }^{(c)}$ Since $\mathrm{NH}_{3}$ and $\mathrm{CH}_{3} \mathrm{NH}_{2}$ have the same desorption behaviour in our vacuum conditions, we used the same desorption rate.

time scale, abundances, and UV flux, we simulated its formation using a reduced chemical reaction network (Eq. (3)),

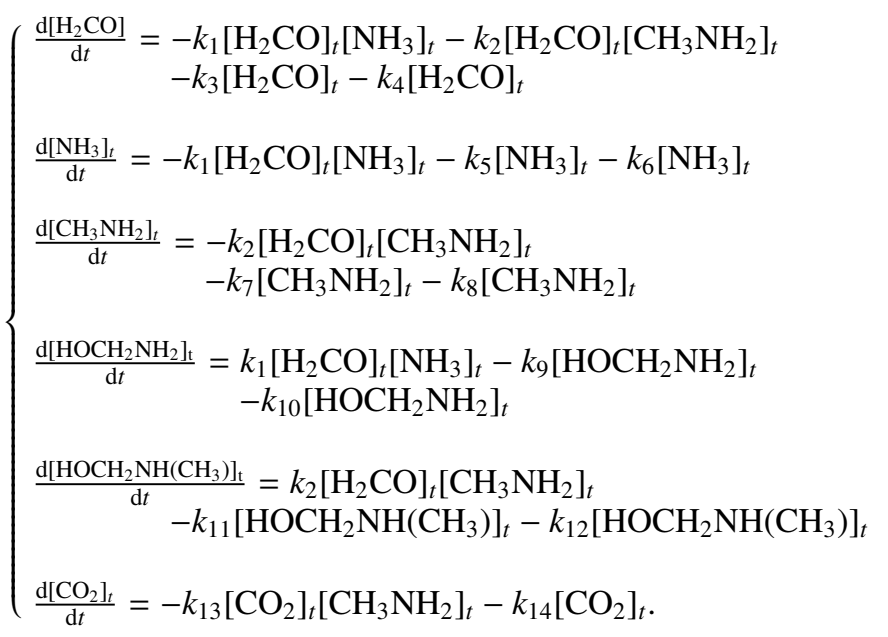

The abundance of $\mathrm{CH}_{3} \mathrm{NHCH}_{2} \mathrm{OH}$ was calculated using a numerical resolution of a system of first-order ordinary differential equations that model the formation and destruction of each species, the water abundance being kept constant (Eq. (3)). Terms in these equations can be sorted into three different classes: thermal formation, thermal desorption, and photodestruction. The photo-destruction term includes two different processes: photo-dissociation and photo-desorption. However, due to our experimental setup, we cannot separate those two phenomena. The reduced chemical reaction network, parameters, and the ordinary differential equation system are shown in Eq. (3), and Table 3. For two-body thermal reactions $\left(k_{1}, k_{2}\right.$, and $\left.k_{13}\right)$ and thermal desorptions $\left(k_{4}, k_{5}, k_{8}, k_{9}, k_{11}\right)$, the rate coefficients are given in the form $k=v_{0} \exp (-E / T)$, where $T$ is the ice temperature, $v_{0}$ the pre-exponential factor, and $E$ the energy (activation or desorption). Two sets of simulation were carried out. The first one neglects diffusion processes, while the second one includes them. In the latter case, we substituted the pre-exponential factor by a new parameter $\left(v_{0}(\right.$ dif $\left.)\right)$, which takes into account the diffusion processes according to the method developed by Hasegawa et al. (1992) (see Table 3). Thus for a two-body thermal reaction including the diffusion between the $i$ and $j$ species, the rate coefficients are given in the form $k=v_{0}(\operatorname{dif}) \exp (-E / T)$. Photo-dissociation rates $\left(k_{3}, k_{6}, k_{7}, k_{10}\right.$, $\left.k_{12}, k_{14}\right)$ are written as $k=\sigma f$, where $\sigma$ represents the photodissociation cross-section for a given species, and $f$ the ultraviolet radiation field depending on the astrophysical environment (Woodall et al. 2007). Kinetic data were used as well as the photo-dissociation cross-section obtained in this work $\left(\sigma_{\text {photo }}\right.$ $\left(\mathrm{CH}_{3} \mathrm{NHCH}_{2} \mathrm{OH}\right)=3 \pm 0.4 \times 10^{-19}$ photon $\left.^{-1} \mathrm{~cm}^{2}\right)$ to estimate kinetic rates of the formation $\left(k_{1}\right)$ and photo-dissociation reactions $\left(k_{12}\right)$ of $\mathrm{CH}_{3} \mathrm{NHCH}_{2} \mathrm{OH}$. The photo-dissociation rates of $\mathrm{CO}_{2}, \mathrm{H}_{2} \mathrm{CO}, \mathrm{NH}_{3}$, and $\mathrm{NH}_{2} \mathrm{CH}_{2} \mathrm{OH}$ were also taken into account using the kinetic rates given in the literature. We also included the desorption rates for all reactants and all products. We included thermal reactions that could compete with the $\mathrm{N}$-methylaminomethanol formation: methylcarbamate (Eq. (4)) and aminomethanol formations (Eq. (5)) (Bossa et al. 2009a,b). All thermal reactions, photo-dissociation, and desorption rates are given in Table 3.

$$
\begin{aligned}
& 2 \mathrm{CH}_{3} \mathrm{NH}_{2}+\mathrm{CO}_{2} \stackrel{\Delta}{\rightarrow} \mathrm{CH}_{3} \mathrm{NH}_{3}^{+} \mathrm{CH}_{3} \mathrm{NHCOO}^{-} \\
& \mathrm{H}_{2} \mathrm{CO}+\mathrm{NH}_{3} \stackrel{\Delta}{\rightarrow} \mathrm{NH}_{2} \mathrm{CH}_{2} \mathrm{OH} .
\end{aligned}
$$

Other reactions that can occur in the ice between $\mathrm{CH}_{3} \mathrm{NH}_{2}$ and acids such as $\mathrm{HNCO}, \mathrm{HCOOH}$, and $\mathrm{HCN}$ are neglected in our simulation since they are supposed to be in lower abundances than $\mathrm{NH}_{3}$ and $\mathrm{CO}_{2}$. The initial ice composition $\mathrm{H}_{2} \mathrm{O} / \mathrm{NH}_{3} / \mathrm{CH}_{3} \mathrm{NH}_{2} / \mathrm{H}_{2} \mathrm{CO} / \mathrm{CO}_{2}=100 / 10 / 1 / 5 / 7$ was chosen according to the average abundances observed in interstellar ices. The temperature and the UV flux were kept constant at $10 \mathrm{~K}$ and $10^{3}$ photons $\mathrm{cm}^{-2} \mathrm{~s}^{-1}$ during the simulation. Simulated abundances of reactants (namely $\mathrm{NH}_{3}$, $\mathrm{H}_{2} \mathrm{CO}, \mathrm{CH}_{3} \mathrm{NH}_{2}$, and $\mathrm{CO}_{2}$ ) are displayed in Fig. 10, while the 


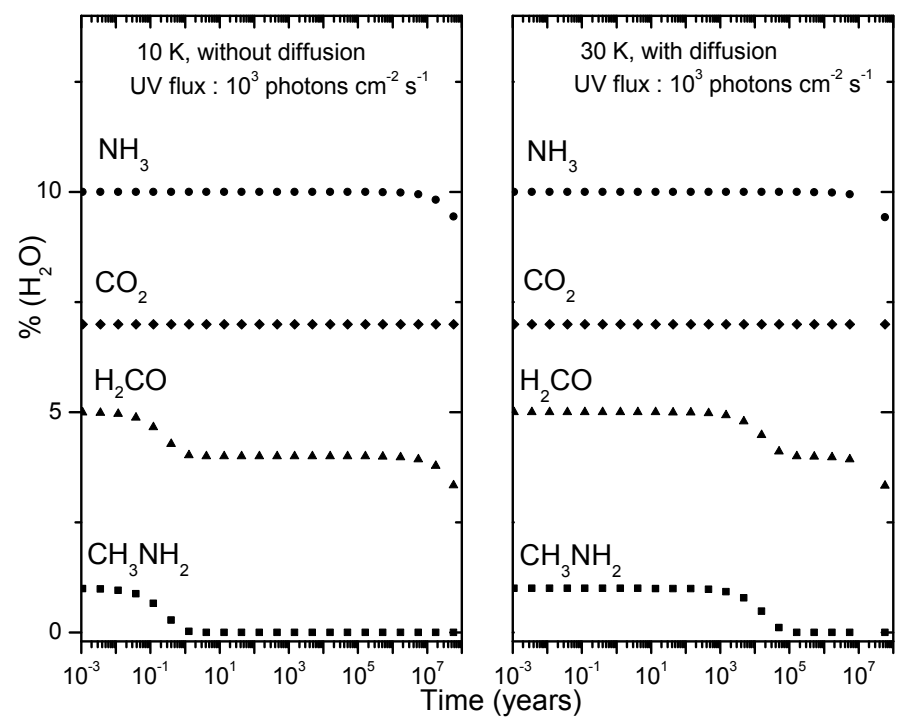

Fig. 10. $\mathrm{H}_{2} \mathrm{CO}$ (full triangle), $\mathrm{NH}_{3}$ (full circle), $\mathrm{CO}_{2}$ (full diamond), $\mathrm{CH}_{3} \mathrm{NH}_{2}$ (full square) simulated abundances in ice as a function of time at $10 \mathrm{~K}$ and in a UV flux of $10^{3}$ photons $\mathrm{cm}^{-2} \mathrm{~s}^{-1}$ without taking into account diffusion processes (left panel), and at $30 \mathrm{~K}$ in a UV flux of $10^{3}$ photons cm $\mathrm{cm}^{-2} \mathrm{~s}^{-1}$ with diffusion processes included (right panel).

abundances of the related products are displayed in Fig. 11. At $10 \mathrm{~K}$, without taking into account the diffusions processes, the abundances of $\mathrm{NH}_{3}$, and $\mathrm{CO}_{2}$ are not affected by thermal activation (Fig. 10). The slow decrease observed for ammonia after $10^{5}$ years is only caused by photo-degradation process. In contrast, in the same conditions, formaldehyde and methylamine quickly react in less than one year (see Fig. 10 left panel) to form the N-methylaminomethanol (see Fig. 11). The maximum concentration (1\% with respect to water) is reached after one year and slowly decreases after $10^{6}$ years through UV degradation. Finally it is fully photolysed, forming the N-methylformamide after $10^{8}$ years (Fig. 11 left panel). In this case methylamine is fully consumed (Fig. 10).

In interstellar ices, molecules are diluted in water, and diffusion of molecules is an important process that will slow down two-body thermal reactions since molecules have to diffuse before reacting. Therefore, we included a diffusion parameter (Hasegawa et al. 1992) in our simulations by changing the preexponential factor $\left(v_{0}\right)$ to a new constant parameter $v_{0}($ dif $)=$ $3.3 \times 10^{-9} \mathrm{~s}^{-1}$. Results are shown in the right panel of Figs. 10 and 11 . In this case formaldehyde and methylamine still react but at higher temperature $(30 \mathrm{~K})$ which can be observed on astrophysical time scales. The methylamine is fully consumed and is not observed after $10^{5}$ years, meaning that in the presence of formaldehyde, methylamine is not likely to be detected in warmed objects. As previously, the N-methylaminomethanol thermally formed was photolysed and fully disappears after $10^{8}$ years, giving the corresponding amide $\left(\mathrm{CH}_{3} \mathrm{NHCHO}\right)$.

According to our simulations, the formation of $\mathrm{N}$-methylaminomethanol from the reaction between formaldehyde and methylamine seems to be possible in interstellar ices when they are gently warmed, as occurs in YSOs, or in comets. However, solid-state identification in interstellar ices from infrared spectra is far from obvious, since some regions are blended by the strong infrared features of both water and silicate (see shaded areas in Fig. 12), and also by the low abundance of these compounds. Aminoalcohols have absorption bands in a clear region in the 5-7 $\mu \mathrm{m}$ wavelength range (Fig. 12),

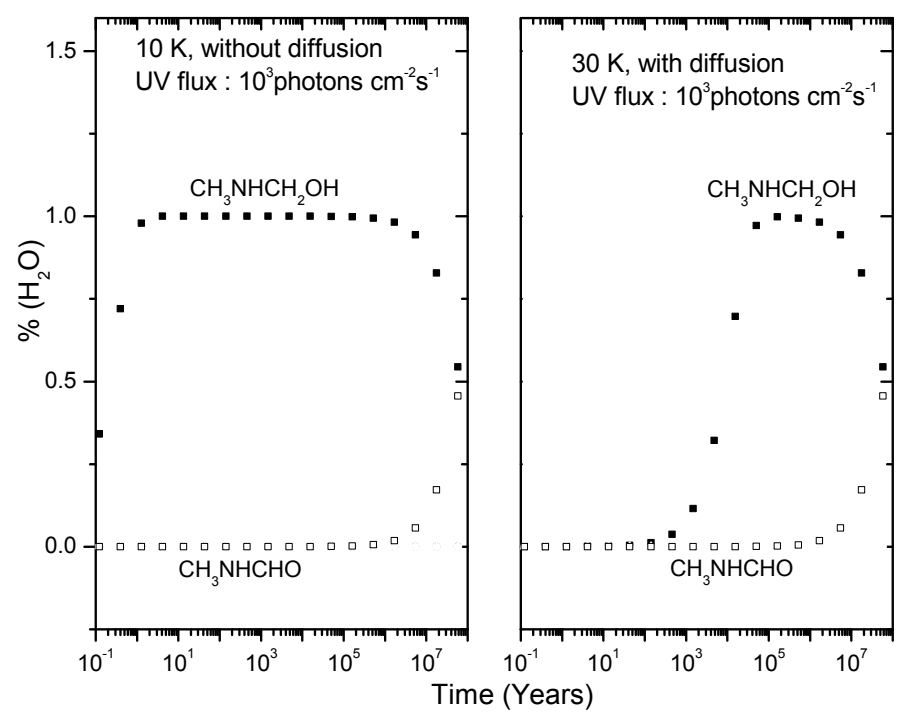

Fig. 11. N-methylaminomethanol $\left(\mathrm{CH}_{3} \mathrm{NHCH}_{2} \mathrm{OH}\right)$ (full square) and $\mathrm{N}$-methylformamide $\left(\mathrm{CH}_{3} \mathrm{NHCHO}\right)$ (open square) simulated abundances in ice as a function of time at $10 \mathrm{~K}$ and in a UV flux of $10^{3}$ photons $\mathrm{cm}^{-2} \mathrm{~s}^{-1}$ without taking into account diffusion processes (left panel), and at $30 \mathrm{~K}$ in a UV flux of $10^{3}$ photons $\mathrm{cm}^{-2} \mathrm{~s}^{-1}$ with diffusion processes included (right panel).

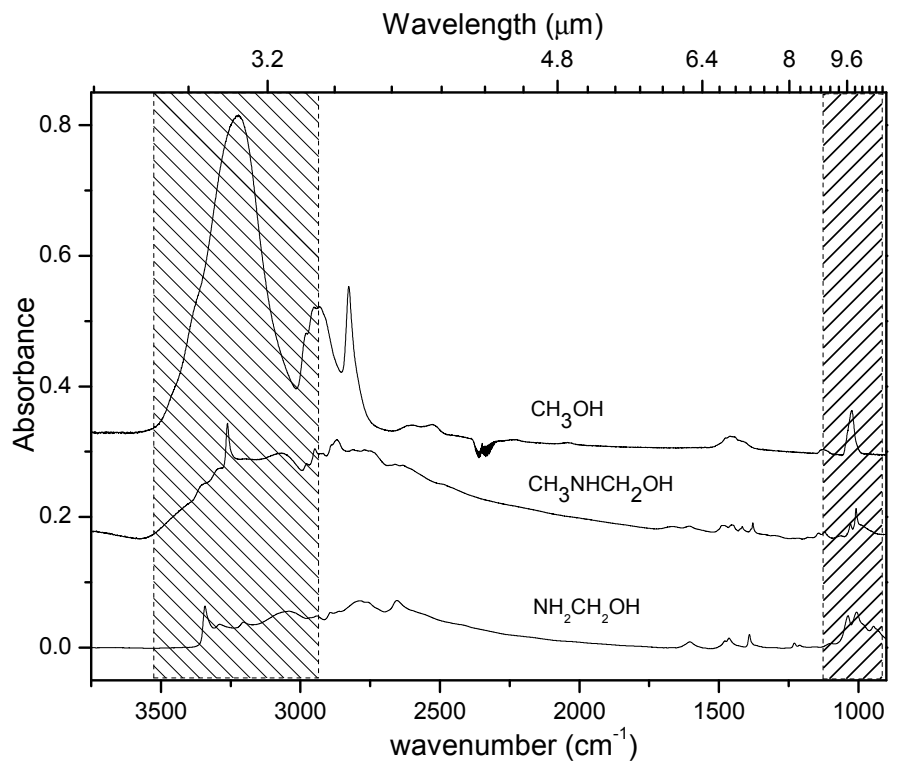

Fig. 12. Infrared spectra of $\mathrm{CH}_{3} \mathrm{OH}, \mathrm{CH}_{3} \mathrm{NHCH}_{2} \mathrm{OH}, \mathrm{NH}_{2} \mathrm{CH}_{2} \mathrm{OH}$ recorded at $10 \mathrm{~K}$. The shaded areas indicate the regions of the strong interstellar $\mathrm{H}_{2} \mathrm{O}$ and silicate absorptions.

and thus could contribute to the 5-7 $\mu \mathrm{m}$ complex, and more specially to the $6,6.85$ and $7.41 \mu \mathrm{m}$ bands that are observed in many astronomical infrared spectra such as W 33A (Fig. 13). W 33A is a high-mass YSO with particularly rich solid-state molecular features (Gibb et al. 2000; Dartois et al. 1999; Keane et al. 2001), with abundant quantities of methanol, which is a signature of an advanced solid-state chemistry. In the bottom panel of Fig. 13 we display the laboratory infrared spectrum of $\mathrm{NH}_{2} \mathrm{CH}_{2} \mathrm{OH}$ in the 5-8 $\mu \mathrm{m}$ range. $\mathrm{NH}_{2} \mathrm{CH}_{2} \mathrm{OH}$ has been proposed to be a possible carrier to the $6 \mu \mathrm{m}$ and $6.85 \mu \mathrm{m}$ bands. In particular its $6.15 \mu \mathrm{m}$ band helps filling in the low-energy half of the $6 \mu \mathrm{m}$ band (Bossa et al. 2009b). The $7 \mu \mathrm{m}$ to $7.5 \mu \mathrm{m}$ regions are also better explained. The same arguments can be used for 


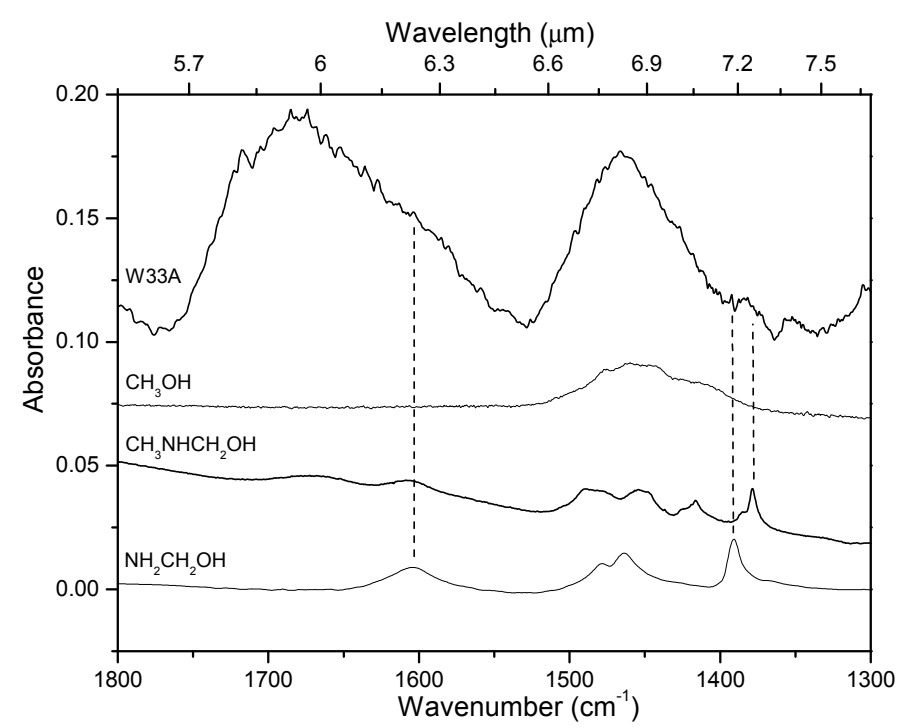

Fig. 13. Comparison between $\mathrm{W} 33 \mathrm{~A}$ and laboratory spectra of $\mathrm{CH}_{3} \mathrm{OH}$, $\mathrm{CH}_{3} \mathrm{NHCH}_{2} \mathrm{OH}$, and $\mathrm{NH}_{2} \mathrm{CH}_{2} \mathrm{OH}$ in the 5.5-7.7 $\mu \mathrm{m}$ range.

the $\mathrm{N}$-methylaminomethanol. The shape of the $\mathrm{CH}_{3} \mathrm{NHCH}_{2} \mathrm{OH}$ $7 \mu \mathrm{m}$ band is similar to the $\mathrm{CH}_{3} \mathrm{OH}$ band, but its $7.20 \mu \mathrm{m}$ feature reproduces the $7.24 \mu \mathrm{m}$ feature in the astronomical spectrum much better (Fig. 13). Although it is not possible to extract reliable abundances for $\mathrm{N}$-methylaminomethanol by deconvolving the astronomical infrared spectra with so many carriers, we can propose that aminoalcohols must be accounted as a carrier of the $5-8 \mu \mathrm{m}$ complex, and that their presence is the signature of a thermal processing of the ice. Furthermore, as many other complex molecules, their detection after sublimation in the hot core region by radio astronomy should be possible. The non-detection so far of these compounds in the gas phase comes from the lack of rotational spectra for these molecules. From an astrobiological point of view, aminoalcohols are interesting molecules because they are considered as amino acid precursors in the Strecker synthesis (Bossa et al. 2009b; Duvernay et al. 2010; Vinogradoff et al. 2011; Rimola et al. 2010; Danger et al. 2011). In our case the $\mathrm{N}$-methylaminomethanol will form through the Strecker synthesis the corresponding amino acid, the sarcosine (Eq. (6)), which has been detected in meteorites (Burton et al. 2012),

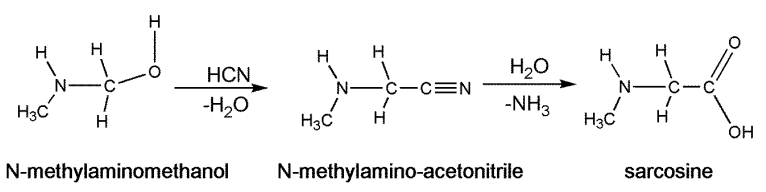

Another interesting aspect that has been underlined in this work is the possibility to induce isotopic fractionation through thermal reaction in ice as is observed in some astrophysical objects. Indeed, some meteoritic materials and interstellar dust particles possess enhancements and anomalies in their $\frac{15}{14} \mathrm{~N}$ ratios. The variability of the $\frac{15}{14} \mathrm{~N}$ ratio in these materials suggest, as with deuterium, a formation induced by low-temperature interstellar chemistry (Charnley \& Rodgers 2002; Kerridge et al. 1987; Messenger \& Walker 1997). To estimate the possible isotopic fractionation between the ${ }^{14} \mathrm{~N}$ methylamine and the corresponding ${ }^{15} \mathrm{~N}$ isotopologue in interstellar ices, we calculated with a reduced kinetic model (Eq. (7)) the $\frac{15 \mathrm{~N}}{14 \mathrm{~N}}$ isotopic ratio at $30 \mathrm{~K}$. We chose for the initial conditions an ice mixture of

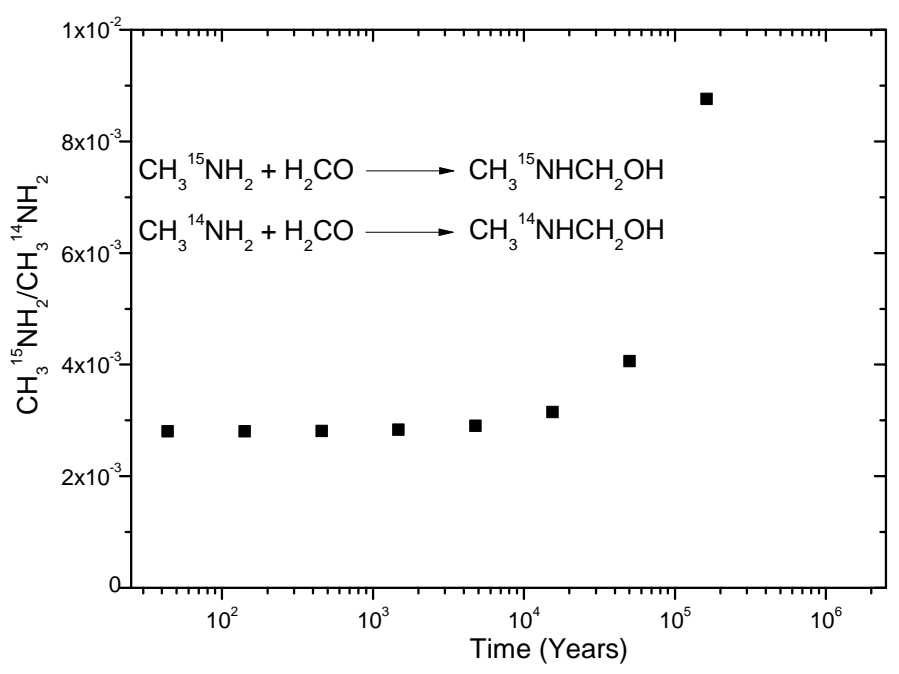

Fig. 14. Evolution of the $\frac{15 \mathrm{~N}}{14 \mathrm{~N}}$ isotopic ratio in methylamine as a function of time at $30 \mathrm{~K}$, considering only the methylamine and formaldehyde reaction.

$\mathrm{H}_{2} \mathrm{O} / \mathrm{CH}_{2} \mathrm{O} / \mathrm{CH}_{3}{ }^{14} \mathrm{NH}_{2} / \mathrm{CH}_{3}{ }^{15} \mathrm{NH}_{2}$ in a $100 / 5 / 1 / 2.8 \times 10^{-3}$ concentration ratio. The $\frac{{ }^{15} \mathrm{~N}}{14 \mathrm{~N}}=2.8 \times 10^{-3}$ isotopic ratio is the value reported for ammonia in dense molecular clouds (Pizzarello \& Williams 2012). The simulation is displayed in Fig. 14. At $30 \mathrm{~K}$, the isotopic ratio for methylamine in ice exponentially increases and reaches the value of $9 \times 10^{-1}$ after $0.5 \times 10^{6}$ years. This result clearly shows that isotopic fractionation at low temperature, induced by thermal reaction, is efficient and has to be taken into account in more sophisticated astrophysical models. Moreover, the ${ }^{15} \mathrm{~N}$ enrichment observed in this simulation is consistent with the increase observed in the ${ }^{15} \mathrm{~N} /{ }^{14} \mathrm{~N}$ ratio between interstellar grains and cometary and meteoritic grains,

$$
\left\{\begin{array}{l}
\frac{\mathrm{d}\left[\mathrm{CH}_{3}{ }^{14} \mathrm{NH}_{2}\right]_{t}}{\mathrm{~d} t}=-k_{14} \mathrm{~N}\left[\mathrm{H}_{2} \mathrm{CO}\right]_{t}\left[\mathrm{CH}_{3}{ }^{14} \mathrm{NH}_{2}\right]_{\mathrm{t}} \\
\frac{\mathrm{d}\left[\mathrm{CH}_{3}{ }^{15} \mathrm{NH}_{2}\right]_{t}}{\mathrm{~d} t}=-k_{15} \mathrm{~N}\left[\mathrm{H}_{2} \mathrm{CO}\right]_{\mathrm{t}}\left[\mathrm{CH}_{3}{ }^{15} \mathrm{NH}_{2}\right]_{t} \\
k_{14} \mathrm{~N}=1.5 \times 10^{-2} \times \mathrm{e}^{-\frac{-1100}{R T}} \\
k_{15 \mathrm{~N}}=2.6 \times 10^{-2} \times \mathrm{e}^{-\frac{-1800}{R T}} .
\end{array}\right.
$$

\section{Conclusion}

We have investigated the thermal formation of $\mathrm{N}$-methylaminomethanol $\left(\mathrm{CH}_{3} \mathrm{NHCH}_{2} \mathrm{OH}\right)$ formation in water ices from formaldehyde $\left(\mathrm{H}_{2} \mathrm{CO}\right)$ and ${ }^{14} \mathrm{~N}$, or ${ }^{15} \mathrm{~N}$ methylamine $\left(\mathrm{CH}_{3}{ }^{14} \mathrm{NH}_{2}\right.$, and $\left.\mathrm{CH}_{3}{ }^{15} \mathrm{NH}_{2}\right)$. We showed that the N-methylaminomethanol formation in interstellar or cometary ices is likely and proposed this molecule as a possible candidate for some infrared features observed in W 33A. In addition, the kinetics study performed with ${ }^{15} \mathrm{~N}$ methylamine shows that these thermal reactions with a low barrier $\left(1.1 \pm 0.05 \mathrm{~kJ} \mathrm{~mol}^{-1}\right)$ are efficient in producing ${ }^{15} \mathrm{~N} /{ }^{14} \mathrm{~N}$ isotopic fractionation. We also investigated the $\mathrm{N}$-methylaminomethanol stability in UV radiation and showed that this molecule leads to the formation of the $\mathrm{N}$-methylformamide. This work provides additional evidences for thermal reactions in interstellar ices as a source of molecular complexity in the ISM. N-methylaminomethanol should be detected in the gas phase when the ices have sublimated, for instance in a hot core region. 
Acknowledgements. This work has been founded by the French national program Physique Chimie du Milieu Interstellaire (PCMI), the Centre National des Études Spatiales (CNES), and the Provence-Alpes-Côte d'Azur region (PACA).

\section{References}

Boogert, A., Pontoppidan, K., Knez, C., et al. 2008, ApJ, 678, 985

Bossa, J., Duvernay, F., Theulé, P., et al. 2009a, A\&A, 506, 601

Bossa, J., Theule, P., Duvernay, F., \& Chiavassa, T. 2009b, ApJ, 707, 1524

Burton, A., Stern, J., Elsila, J., Glavin, D., \& Dworkin, J. 2012, Chem. Soc. Rev., 41,5459

Charnley, S., \& Rodgers, S. 2002, ApJ, 569, L133

Chen, L., \& Woon, D. 2011, J. Phys. Chem. A, 115, 5166

Cottin, H., Moore, M., \& Bénilan, Y. 2003, ApJ, 590, 874

Danger, G., Borget, F., Chomat, M., et al. 2011, A\&A, 535, A47

Dartois, E., Schutte, W., Geballe, T., et al. 1999, A\&A, 342, L32 Duvernay, F., Chiavassa, T., Borget, F., \& Aycard, J. 2004, Chem. Phys., 298,
241

Duvernay, F., Chatron-Michaud, P., Borget, F., Birney, D. M., \& Chiavassa, T. 2007, Phys. Chem. Chem. Phys., 9, 1099

Duvernay, F., Dufauret, V., Danger, G., et al. 2010, A\&A, 523, A79

Elsila, J., Glavin, D., \& Dworkin, J. 2009, Meteor. Planet. Sci., 44, 1323

Fayolle, E., Bertin, M., Romanzin, C., et al. 2011, ApJ, 739, L36

Fourikis, N., Takagi, K., \& Morimoto, M. 1974, ApJ, 191, L139

Frisch, M., Trucks, G., Schlegel, H., et al. 1998, Gaussian 98, revision A. 7, Gaussian, Vol. 25

Gardner, E., \& McNesby, J. 1982, J. Phys. Chem., 86, 2646

Gibb, E., Whittet, D., Schutte, W., et al. 2000, ApJ, 536, 347
Godfrey, R., Brown, R., Robinson, B., \& Sinclair, M. 1973, Discovery of interstellar methanimine (formaldimine)., Tech. rep., Monash Univ., Melbourne Hasegawa, T., Herbst, E., \& Leung, C. 1992, ApJS, 82, 167

Herbst, E. 1985, ApJ, 292, 484

Hiraoka, K., Ohashi, N., Kihara, Y., et al. 1994, Chem. Phys. Lett., 229, 408

Hiraoka, K., Sato, T., Sato, S., et al. 2002, ApJ, 577, 265

Holtom, P., Bennett, C., Osamura, Y., Mason, N., \& Kaiser, R. 2005, ApJ, 626, 940

Keane, J., Tielens, A., Boogert, A., Schutte, W., \& Whittet, D. 2001, A\&A, 376, 254

Kerridge, J., Chang, S., \& Shipp, R. 1987, Geochim. Cosmochim. Acta, 51, 2527

Lee, C., Yang, W., \& Parr, R. 1988, Phys. Rev. B, 37, 785

Messenger, S., \& Walker, R. 1997, in AIP Conf. Proc., 402, 545

Öberg, K., Garrod, R., VAN Dishoeck, E., \& Linnartz, H. 2009, A\&A, 504, 891

Ogura, K., Migita, C., \& Yamada, T. 1989, J. Photochem. Photobiol. A: Chem., 49, 53

Pizzarello, S., \& Williams, L. 2012, ApJ, 749, 161

Rimola, A., Sodupe, M., \& Ugliengo, P. 2010, Phys. Chem. Chem. Phys., 12, 5285

Schutte, W., Allamandola, L., \& Sandford, S. 1993, Icarus, 104, 118

Shin, S., Kurawaki, A., Hamada, Y., et al. 2006, J. Mol. Struct., 791, 30

Theule, P., Borget, F., Mispelaer, F., et al. 2011, A\&A, 534, A64

Vinogradoff, V., Duvernay, F., Danger, G., Theulé, P., \& Chiavassa, T. 2011, A\&A, 530, A128

Watanabe, N., Nagaoka, A., Shiraki, T., \& Kouchi, A. 2004, ApJ, 616, 638

Woodall, J., Agúndez, M., Markwick-Kemper, A., \& Millar, T. 2007, A\&A, 466, 1197 